\title{
Participation Status of Charities in Iran's Health System
}

\author{
Raana Gholamzadeh Nikjoo (iD ${ }^{1}$, Nasrin Joudyian (iD ${ }^{2,}{ }^{*}$ and Yegane Partovi (iD) ${ }^{2}$ \\ ${ }^{1}$ Department of Health Policy \& Management, Tabriz Health Services Management Research Center, School of Management \& Medical Informatics, Tabriz University of \\ Medical Sciences, Tabriz, Iran \\ ${ }^{2}$ Iranian Center of Excellence in Health Management, Department of Health Policy and Health Services Management, School of Management and Medical Informatics, Tabriz \\ University of Medical Sciences, Tabriz, Iran \\ "Corresponding author: Iranian Center of Excellence in Health Management, Department of Health Policy and Health Services Management, School of Management and \\ Medical Informatics, Tabriz University of Medical Sciences, Tabriz, Iran. Email: njoudiyan.9170@gmail.com
}

Received 2020 December 06; Revised 2021 May 31; Accepted 2021 July 09.

\begin{abstract}
Objective: This study aimed to reflect on the participation status of charities at different levels (i.e., prevention, treatment, and rehabilitation) of Iran's health care system.

Methods: This descriptive cross-sectional study was fulfilled in 2019 based on 40 charitable organizations involved in health care services delivery, which were randomly selected from the Iranian Charities Portal (ICP). Data were collected via a valid and reliable researcher-made questionnaire. SPSS software version 16.0 was used to analyze data.

Results: Direct and indirect methods of service delivery were used in 63\% of organizations. The most important sources of funding were associated with public donations. Furthermore, 94\% of charities were evaluating the health care services with internal and external evaluation and customer satisfaction surveys.

Conclusions: The charities could be a precious contribution to the health care system. To use this potential as a synergistic factor of the health system, adopting such strategies as creating sustainable funding sources and establishing more coordination between organizations are essential.
\end{abstract}

Keywords: Health Care System, Charities

\section{Background}

The main purpose of health care systems is to systematize individuals, organizations, and resources for providing health care services to meet the needs of target populations (1).

All health care systems face the challenge of insufficient resources, and they lack the capacity to provide all services that people need. Despite the immediate actions taken by governments, some human needs have always been in a way that neither governments nor private sectors have been able to meet them. Therefore, some specific organizations, including charities, have been founded to address such needs (2-4).

Given these valuable potentials, more coordination between charities and other health care system components is a necessity.

\section{Objectives}

The present study aimed to reflect on the participation status of charities at different levels of Iran's health care system.

\section{Methods}

This descriptive cross-sectional study was conducted in 2019. To collect the data, the Iranian Charities Portal (ICP) was searched. In the first phase, out of 804 active charitable organizations identified in the fields of health care services, 129 cases were removed from the study due to their irrelevant activities. The remaining 675 charitable organizations were considered, which were active in three levels, including prevention ( $n=255)$, treatment $(n=438)$, and rehabilitation $(n=68)$.

Based on the statistical calculations and the Cochran's formula, 40 charitable organizations were selected by stratified sampling method as the study samples at three levels. Data was gathered using a researcher-made questionnaire. To examine the validity and reliability of the measure, it was submitted to 10 professors and experts in this field, and then, the content validity of the questionnaire was measured and confirmed (content validity index: $\mathrm{CVI}=0.95$ and content validity ratio: $\mathrm{CVR}=0.89)$. Also, the measure had excellent internal consistency $(\alpha=0.82)$. Then, the questionnaire was sent via e-mail or fax to the or- 
ganizations, or it was completed through telephone interviews with authorities of the organizations. We considered two to three weeks as a time interval to complete the questionnaire. Meanwhile, follow-up was done at least three times to collect the data. Data analysis was performed using SPSS software version 16 and reported using descriptive statistics.

\section{Results}

Out of 40 charitable organizations included in his study, 33 cases completed the questionnaire. Analysis of demographic characteristics of the sample showed that the highest distribution was related to charitable organizations in Tehran Province $(\mathrm{n}=12,36 \%)$.

The charitable organizations were providing health care services to certain target populations (Table 1). Following their fields of activity, each organization was providing its health care services in the form of community-based educational-preventive services, medical-pharmaceutical services for patients, rehabilitation-welfare-supportive services (including financial and legal services), patientcentered educational-preventive services, equipment and infrastructure development services, construction of health infrastructure, and research services (Appendix1).

Evaluation of health care service delivery in these charitable organizations revealed that $63 \%$ of them were using direct (i.e., service delivery) and indirect (i.e., financial support) methods of providing services to target populations. In $60.6 \%$ of these organizations, the most important funding sources were related to public donations. Also, $94 \%$ of the organizations were evaluating health care services.

Charitable organizations have always faced challenges in achieving their goals. These challenges were accordingly examined among the given charities and then classified into five categories, including informational, financial, human, physical, and legal-supportive. The proposed solutions appropriate to each challenge were subsequently presented (Table 2 ).

\section{Discussion}

We witnessed that the charities were providing health care services to the target populations at three different levels with direct and indirect methods of service delivery. It is possible to make the best use of the capacities of volunteers to improve the health status of communities, especially in the field of prevention. Accordingly, installing booths in public places with a focus on prevention and healthy lifestyle and producing educational videos and publishing them on social networks, as well as providing health education at the community level in a variety of formats tailored to the target populations, can be among effective strategies in this area.

Charitable organizations can take growing steps in this direction by adopting methods such as developing an operational plan to achieve the goals in organizations with a focus on attracting sustainable financial resources, as well as planning to empower charities to generate revenues through marketing and sales services to the government and the private sector. It is also suggested that these organizations involve in planning processes and giving advisory and sometimes supervisory positions in advancing the goals of the health care system (5-8).

\subsection{Limitations}

In this study, despite a comprehensive investigation of charitable organizations, we faced some limitations regarding the cooperation of organizations active in the field of acquired immunodeficiency syndrome (AIDS), as well as the unavailability of some organizations due to relocation, which need to be investigated in future research.

\section{Acknowledgments}

We would like to thank all the charities that helped us during the study process.

\section{Footnotes}

Authors' Contribution: JN, GhNR, and PY contributed equally to this study.

Conflict of Interests: The authors declare that there is no conflict of interest.

Ethical Approval: IR.TUMS.NIHR.REC.1396.51.

Funding/Support: This research was supported by the National Institute of Health Research of Iran and Tabriz University of Medical Sciences. 


\begin{tabular}{ll}
\hline Table 1. Demographic Characteristics of Charitable Organizations & Percentage (\%) \\
\hline Demographic Characteristics & \\
\hline Covered population groups & \\
\hline Thalassemia, hemophilia, multiple sclerosis (MS), renal failure, heart diseases, muscular dystrophy, hearing loss and visual problems, \\
diabetes, types of cancer, phenylketonuria, and epilepsy, and individuals with disabilities \\
\hline Service delivery methods \\
\hline Direct (service delivery) and indirect (financial support) methods & 24 \\
\hline Direct method & 63 \\
\hline Indirect method & 6 \\
\hline Service purchase method: direct and indirect & 60.6 \\
\hline Sources of funding & 15.15 \\
\hline Public donations & 12.12 \\
\hline Donations from NGOs & 6.06 \\
\hline Government aids & 6.06 \\
\hline Public donations, donations from NGOs, government aids, and customer service fees & \\
\hline Other methods: incomes from cultural and social projects, advertising revenues of pharmaceutical and medical equipment companies, and & \\
\hline membership fees & \\
\hline Service evaluation methods & 19.35 \\
\hline Customer satisfaction & 19.35 \\
\hline External evaluation (i.e., external monitoring and control) & 12.90 \\
\hline Internal and external evaluation & 6.45 \\
\hline Internal evaluation & 6.45 \\
\hline Customer satisfaction and internal evaluation & 6.45 \\
\hline Customer satisfaction and external evaluation & \\
\hline
\end{tabular}

\begin{tabular}{|c|c|c|}
\hline Items & Challenges & Suggested Solutions \\
\hline \multicolumn{3}{|l|}{ Resources } \\
\hline Informational & $\begin{array}{l}\text { Low awareness of diseases in community and patient families; } \\
\text { Uncertainty of insurance tariffs for specialized home care and relief } \\
\text { care services }\end{array}$ & $\begin{array}{l}\text { Raising awareness at community level and in families and officials; } \\
\text { Determining insurance tariffs for home care services; Conducting } \\
\text { research and developing a home care justification plan for } \\
\text { insurance companies }\end{array}$ \\
\hline Financial & $\begin{array}{l}\text { Limited financial resources allocated to specific diseases; Lack of } \\
\text { budgets and rising drug prices; Currency fluctuations; Financing of } \\
\text { most donations due to economic conditions; Increasing costs of } \\
\text { dentistry and tests for specific patients; High costs of consumer } \\
\text { equipment for cancer patients; Poor economic situation and high } \\
\text { drug prices }\end{array}$ & $\begin{array}{l}\text { Creating continuous and sustainable sources of income; } \\
\text { Monitoring prices and distribution of items, as well as reducing } \\
\text { intermediation; Providing charities with government resources }\end{array}$ \\
\hline human & $\begin{array}{l}\text { Lack of cooperation between government officials and failure to } \\
\text { fulfill their promises; No cooperation between public media and } \\
\text { officials in achieving goals of informing the public and introducing } \\
\text { associations' services to citizens; Insufficient coordination between } \\
\text { government agencies; Low cooperation between patients and their } \\
\text { families with association programs; Absence of specialized } \\
\text { personnel; Difference between charitable programs and those by } \\
\text { the government }\end{array}$ & $\begin{array}{l}\text { Making comprehensive efforts to help and facilitate patient affairs; } \\
\text { Limiting abuse of authorities and encouraging cooperation of } \\
\text { related charities; Stimulating cooperation by all officials, especially } \\
\text { public media, for providing continuous information about } \\
\text { diseases; Establishing coordination between government agencies; } \\
\text { Prioritizing programs; Inspiring inter-sectorial coordination and } \\
\text { cooperation between NGOs and executive bodies }\end{array}$ \\
\hline Physical & $\begin{array}{l}\text { Allocation of minimum government facilities to diseases; Improper } \\
\text { and unplanned increase in the number of charitable organizations } \\
\text { and prevalence of modern begging; Lack of training place; Shortage } \\
\text { of some drugs }\end{array}$ & Forming an organization to coordinate NGOs \\
\hline legal-supportive & $\begin{array}{l}\text { Removal of majority of medicines from the coverage of insurance } \\
\text { organizations; Insufficient support from the government and } \\
\text { responsible bodies; Lack of reference organizations for inquiry; } \\
\text { Non-participation of NGOs in decision-making and related } \\
\text { executive programs; Lack of positions in specialized committees of } \\
\text { public and private organizations affiliated to the Ministry of Health } \\
\text { and Medical Education; No clear laws for use of volunteer } \\
\text { workforce in charitable organizations }\end{array}$ & $\begin{array}{l}\text { Providing insurance support for rehabilitation of the disabled; } \\
\text { Identifying participation status of NGOs in decision-making }\end{array}$ \\
\hline
\end{tabular}




\section{References}

1. World Health Organization; Organisation for Economic Co-operation and Development \&amp; International Bank for Reconstruction and Development. Delivering quality health services: a global imperative for universal health coverage. World Health Organization; 2018. Available from: https://apps.who.int/iris/handle/10665/272465.

2. Colbran R, Ramsden R, Stagnitti K, Toumbourou JW. Advancing towards contemporary practice: a systematic review of organisational performance measures for non-acute health charities. BMC Health Serv Res. 2019;19(1):132. doi: 10.1186/s12913-019-3952-1. [PubMed: 30795742]. [PubMed Central: PMC6387497].

3. Ejaz I, Shaikh BT, Rizvi N. NGOs and government partnership for health systems strengthening: a qualitative study presenting viewpoints of government, NGOs and donors in Pakistan. BMC Health
Serv Res. 2011;11:122. doi: 10.1186/1472-6963-11-122. [PubMed: 21609480]. [PubMed Central: PMC3112396].

4. Hillis V, Lubell M, Hoffman M. Sustainability partnerships and viticulture management in California.J Environ Manage. 2018;217:214-25. doi: 10.1016/j.jenvman.2018.03.033. [PubMed: 29604415].

5. Boateng A, Akamavi RK, Ndoro G. Measuring performance of nonprofit organisations: evidence from large charities. Bus Ethics. 2016;25(1):59-74. doi: 10.1111/beer.12108.

6. Bromideh AA. The widespread challenges of NGOs in developing countries: Case studies from Iran. Int NGO J. 2011;6(9):197-202.

7. Nekoeimoghadam M, Amiyousefi S, Ghorbani BZ, Amiresmaili M. [Role of charities in the health system: A qualitative study].J Qual Res Health Sci. 2013;2(1):1-10. Persian.

8. Rohde M. Building an e-community of Iranian NGOs. Proceedings of IADIS International Conference on e-Society. Portugal. 2003. p. 187-94. 